\title{
Counteracting Free-Riding With Team Morale-An Experimental Study
}

Jun He, College of Business, University of Michigan-Dearborn, Dearborn, MI, USA

ABSTRACT

This study focuses on a behavioral perspective to examine the detrimental effects of freeriding on team performance, and investigates team morale as a key factor that counteracts the tendency of free-riding among team members. Results of the empirical test imply that enhancing team morale can effectively reduce the scale of free-riding behavior in project teams; in addition, controlling team size also provides help to constrain the undesired behavior. The two means can be carefully applied to project management during early stages of project development before the commitment of significant resources. Implications for both research and team practices are discussed.

KEYWORDS: free-riding; organizational citizenship behavior; team cognition; team morale; team performance

Project Management Journal, Vol. 43, No. 3, 62-75 (C) 2012 by the Project Management Institute Published online in Wiley Online Library (wileyonlinelibrary.com). DOI: 10.1002/pmj.21272

\section{INTRODUCTION}

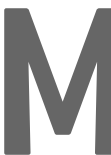

odern organizations have widely adopted the team approach as a way of accomplishing tasks that surpass the capabilities of single individuals (Glassop, 2002). Teams are viewed as "group(s) of two or more individuals who must interact cooperatively and adaptively in pursuit of shared valued objectives" (Cannon-Bowers, Salas, \& Converse, 1993, p. 223). To achieve team success, team members should engage in collective actions and restrict individual activities that are incompatible with or even contradictory to team objectives. Of the undesirable behaviors, free-riding has long been argued to be a main obstacle for teams to achieve quality performance (Anesi, 2009; Kerr, 1983; Olson, 1965; Orbell \& Dawes, 1981; Price, 2006).

Free-riding, also labeled as a social trap (Platt, 1973), commons problem (Edney, 1980), commons dilemma (Dawes, McTavish, \& Shaklee, 1977), assurance problem (Runge, 1984), social loafing (Karau \& Williams, 1993; Orbell \& Dawes, 1981), and moral hazard in teams (Anesi, 2009), refers to an undesired behavior in which a member of a group obtains benefits from group membership but does not bear a proportional share of the costs of providing the benefits (Albanese \& Van Fleet, 1985). Free-riding deteriorates team productivity by tempting team members to be free-riders and shirk from collective actions.

Given free-riding's role in determining team success, many studies have been conducted to understand and develop a means to cope with this detrimental behavior. Early group and organizational theorists have focused on the causes of free-riding under the theoretical umbrella of public goods (e.g., Albanese \& Van Fleet, 1985; Olson, 1965; Orbell \& Dawes, 1981; Runge, 1984; Stroebe \& Frey, 1982); experimental studies derived from the prisoner's dilemma game (Albanese \& Van Fleet, 1985; Luce \& Raiffa, 1957) and public goods provisioning (Dawes, 1980) have been conducted to study how group size, nature of task, individual differences, and work arrangements affect one's tendency of free-riding (for a review, see Albanese \& Van Fleet, 1985). Research in this area employs mathematic modeling to examine reward/sanction systems under which free-riding behaviors can be discouraged (e.g., Anesi, 2009; Price, 2006; van Dijk, Sonnemans, \& van Winden, 2001). In addition, the advance of information technology opens a new arena for studying technologies, especially communication technologies, in affecting people's behavior in technology-supported team settings (e.g., Alnuaimi, Robert, \& Maruping, 2010).

However, our understanding of free-riding is still not perfect. With much attention being placed on explicit means such as group composition, technologies, and reward/sanction systems, behavioral research that examines the extent to which cognitive, psychological, social, and cultural factors affect people's free-riding tendency is comparatively rare. Albanese and Van Fleet's (1985) criticism remains valid today that the research falls short of clear conclusions regarding what managerial methods can be applied to 
effectively counter the free-riding tendency in project teams.

To fill the research gap, this study takes a behavioral perspective to examine the detrimental effects of freeriding on team performance based on the recent development of social and cognitive theories, and investigates team morale, or the collective task attitudes shared by team members, as a key factor that counteracts the tendency of free-riding among team members.

The remainder of the article is organized as follows. First, a brief literature review on free-riding, organizational citizenship behavior (OCB), and team cognition in social and organizational behavior is presented, followed by the proposal of a research model with team morale and team size as the antecedents and team cognition and team performance as the consequences of free-riding. Then, a research strategy is designed with the use of student software development teams as the research subject. An instrument is developed to capture salient free-riding behaviors from team members. After empirical testing of the research model, results and implications of the study are discussed.

\section{Theoretical Foundations and Hypotheses}

This study intends to investigate the antecedents as well as the consequences of free-riding in team settings. A research model is presented in Figure 1.

\section{Free-Riding}

The notion of free-riding can be backdated to the early seminal work of Olson (1965). Of the large literature on inefficiencies in collective actions, all studies point to the free-rider problem as a main obstacle in achieving the desired outcomes (Anesi, 2009). The cause of free-riding is rather intuitive. Price (2006) summarized the cause as follows:

If each member receives an equal share of the benefit that the group

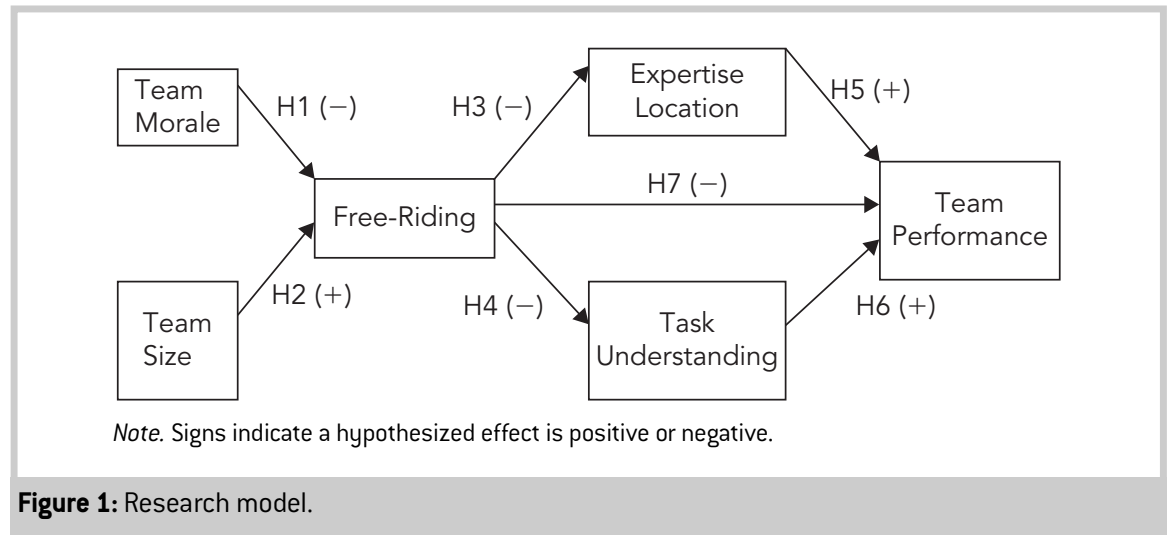

produces, no matter how much that member contributed to the production effort, then each member has a private incentive to contribute less than co-members. This incentive to free-ride exists because if all members benefit equally, then the members who contributed the least to production will reap the highest net benefits. (p. 20)

There are two assumptions about human nature underlying the above analysis: (1) people are egoistic so that personal interests always surpass collective benefits of others, and (2) people are rational so that they tend to perform activities whose perceived benefits outweigh perceived costs. The assumptions are in line with the transaction cost theory, which presumes that economic actors behave with bounded rationality and self-interest (Simon, 1976; Williamson, 1985), and some are either opportunistic or untrustworthy (Williamson, 1985). A central premise of transaction cost theory is that "employees will have strong incentives to shirk (from work) and no incentive to improve performance unless task conditions allow employees to demonstrate discrete performance contributions and to obtain the rewards that accrue from increased performance" (Jones, 1984, p. 5). As such, people tend to act selfishly and shirk from assigned tasks if their behavior cannot be monitored and evaluated in a team environment. The literature suggests two solutions to the free-rider problem: (1) designing reward systems to direct social benefits toward cooperators and/ or (2) designing sanction systems to impose social costs on free-riders (Andreoni, Harbaugh, \& Vesterlund, 2003; Fehr \& Gächter, 2000; Hawkes, 1993; Price, 2006; Yamagishi, 1986). The two solutions share a common theme: reducing the incentive (the difference between the estimated benefits and costs) to free-ride in order to encourage one's participation in collective activities.

However, designing new reward/ sanction systems could be very challenging, if not intimidating, in many situations. Especially when tasks are unique, complex, or ambiguous, standardized monitoring and merit-reward systems should be precluded for the ambiguity of performance evaluation (Ouchi, 1980). Other approaches need to be explored to address the free-rider problem. The research on OCB provides another perspective on studying this issue.

\section{Team Morale and Organizational Citizenship Behavior}

People are not always self-centered. An individual's behavior in collective actions is driven not only by rational calculation of material incentives, but also by immaterial motivations such as normative conformity (socially accepted standards of conduct about principled behavior) and affective bond (emotional attachments to certain 
people and organizations) (Kidwell \& Bennett, 1993; Knoke, 1988). In addition, researchers have noted the existence of altruistic behavior in organizational settings where people make voluntary efforts at work beyond prescribed specifications and tasks. Such behaviors are labeled as organizational citizenship behaviors (OCBs) in the literature. OCB that was derived from Organ's (1988) work has received the most research attention (Hoffman, Blair, Meriac, \&Woehr, 2007). According to Organ (1988), OCB refers to:

individual behavior that is discretionary, not directly or explicitly recognized by the formal reward system, and that in the aggregate promotes the effective functioning of the organization. By discretionary, I mean that the behavior is ... rather a matter of personal choice, such that its omission is not generally understood as punishable. (p. 4)

OCB can be viewed as an extreme opposite of free-riding behaviors. Freeriding is driven by personal interests, while OCB promotes collective benefits by voluntary activities. OCB research implies alternative solutions to counteract free-riding without the burden of designing new reward/sanction systems.

A comprehensive review of the literature concludes that job attitudes are robust predictors of OCB (Organ \& Ryan, 1995). Positive job attitudes such as commitment to work reflect that employees identify with the organization's values, accept its goals, and are willing to make significant efforts at work (J. P. Meyer \& Herscovitch, 2001), and OCB is one of the main consequences that benefits the organization by promoting efficiency and effective functioning (Organ, 1988; Organ, Podsakoff, \& MacKenzie, 2006). Thus, organizations are encouraged to maintain high morale among the workforce for favorable behaviors of OCB (Randall, Cropanzano, Bormann, \& Birjulin, 1999). The positive influence of job attitudes on OCB has received strong support from empirical research. In a study of temporary workers, researchers find that employees with strong job commitment and motivations to taking assignments present high levels of OCB in client organizations (Moorman \& Harland, 2002). In another study of self-directed teams, team commitment was found to be positively correlated ( $r=0.4, p<0.001$ ) with the tendency of OCB (Foote \& Tang, 2008). Although much of the research is conducted within the US context, similar results have been concluded from other cultures, including Australia (Feather \& Rauter, 2004), Korea (Kim, 2006), Spain (Vilela, González, \& Ferrín, 2008), and France (Paillé, 2010), to name a few.

By definition, the presence of OCB means the lack of free-riding behaviors. People who have positive attitudes and strong commitments about their work are less likely to be free-riders when working with their colleagues. In cohesive social networks such as project teams, people's perceptions of and attitudes about their assignments are largely determined by social influence from peers (Latane, 1981; G. W. Meyer, 1994; Salancik \& Pfeffer, 1978). Thus, a team's collective attitude about team tasks will affect individuals' attitudes, and therefore their behaviors, about participating in team actions. The more positive the collective attitude is about the tasks, the less likely that team members will shirk in team activities and be free-riders.

Following the work of Lindsay, Manning, and Petrick (1991), team morale is defined in the study as the collective attitudes and shared commitments among members with regard to their team tasks. Project teams with high team morale present a strong sense of shared significance of team tasks and a commitment to peak performance, and exert persistent social influence on members, as their teammates commonly expect collaborative behaviors guided by team interests.
In contrast, members of teams with low team morale observe weak social influence and feel limited constraints on their private behaviors. Kappelman, McKeeman, and Zhang (2006, p. 34) note, "Project team members with a weak commitment to the project scope and schedule can always find other worthwhile activities to work on." In summary, team morale will counter the tendency of free-riding in a project team.

Hypothesis 1: Team morale has a negative effect on the scale of freeriding in a team: the higher the team morale, the less manifest is the freeriding behavior in the team.

\section{Team Size}

Other than team morale, the study investigates team size as another antecedent factor that exerts significant effects on free-riding. Team size can be viewed as a control variable in the research model (Figure 1) because it (1) serves as a background variable that describes a distinct aspect (i.e., the number of members) of investigated teams and (2) complements the focal analysis of team morale. Including background variables as control variables helps to alleviate the concern of coverage error and improve the generalizability of the results of empirical research (King \& He, 2005).

Indeed, the effect of team size on free-riding has long been discussed in the literature. The free-rider problem is rooted in the rational comparison between the expected benefits and estimated costs of free-riding (Olson, 1965; Price, 2006). The difference, viewed as an incentive, grows with the number of people involved in the target collective action (Albanese \& Van Fleet, 1985; Anesi, 2009). Compared with small groups, individuals in large groups are more likely to conclude that there is no perceptible difference between contributing and not contributing, therefore increasing the tendency of free-riding (Albanese \& Van Fleet, 1985). In addition, large team sizes 
make the interaction between members more difficult and complex (Riopelle et al., 2003), thereby increasing the likelihood of free-riding behaviors, especially in technology-supported teams (Alnuaimi et al., 2010; Chidambaram \& Tung, 2005). Thus, large teams are expected to be the most affected by the free-rider problem.

Hypothesis 2: Team size has a positive effect on the scale of free-riding in a team: the larger the team size, the more manifestis the free-riding behavior in the team.

\section{Team Cognition and Team Performance}

Team cognition refers to the mental models collectively held by a group of individuals that enable them to accomplish tasks by acting as a coordinated unit. This team-level integration of mental models functions as a mental template that is imposed on information environments to give them form and meaning, providing a cognitive foundation for action (Walsh, 1995).

The concept of team cognition has been proposed as a valid theoretical lens for examining team interactions (Cannon-Bowers et al., 1993; Cooke, Salas, Kiekel, \& Bell, 2004; Klimoski \& Mohammed, 1994). Effective teams need to exchange and process information and knowledge among team members. Such team interactions require both time and cognitive resources (MacMillan, Estin, \& Serfaty, 2004). Team cognition enables members to formulate accurate teamwork and task work predictions (Cannon-Bowers et al., 1993; Katz \& Tushman, 1979), adapt their activities and behaviors in a collaborative way, and therefore increase overall team effectiveness (Cannon-Bowers \& Salas, 2001; Lewis, 2004). Without wellformed team cognition, team members will not be able to efficiently share knowledge and information, coordinate each other's activities, resolve conflicts, or negotiate agreed-upon solutions (Cannon-Bowers \& Salas,
2001; Jackson, May, \& Whitney, 1995; Walsh, 1995).

There are different types of team cognition (for a review, see CannonBowers \& Salas, 2001). Among them, team types and task types of team cognition are most relevant for team performance (Mathieu, Goodwin, Heffner, Salas, \& Cannon-Bowers, 2000). In a study of student software development teams, He, Butter, and King (2007) identified shared awareness of expertise location and shared task understanding as two key dimensions of team cognition. Shared awareness of expertise location refers to members' shared awareness of other members' knowledge and expertise in the team; shared task understanding refers to the mutually shared understanding of a focal task among team members.

The development of team cognition requires frequent interactions among team members such as communications and working together (Cooke et al., 2004; He et al., 2007; Klimoski \& Mohammed, 1994). Free-riding, however, impedes the development of team cognition by inducing individuals to shirk from collective actions. With regard to the two main dimensions of team cognition, the following two hypotheses are proposed:

Hypothesis 3: The scale of free-riding has a negative effect on the level of shared awareness of expertise location in a team.

Hypothesis 4: The scale of free-riding has a negative effect on the level of shared task understanding in a team.

The team cognition research has repeatedly observed that teams perform better if they have developed mature team cognition (He et al., 2007; Hollingshead, 1998; Lewis, 2004; Liang, Moreland, \& Argote, 1995; Moreland \& Myaskovsky, 2000). The empirical evidence supports team cognition as an important determinant for the effectiveness of working teams (CannonBowers \& Salas, 2001; Mohammed \&
Dumville, 2001; Walsh, 1995), although various mechanisms may exist for different dimensions of team cognition to affect team performance. More specifically, shared awareness of expertise location contributes to better team performance by (1) enabling members to anticipate, rather than simply react to, one another's behavior (Murnighan \& Conlon, 1991); (2) enhancing members' ability to access one another's specialized expertise, resulting in an expanded pool of knowledge and expertise for decision making and problem solving (Hollingshead, 1998); and (3) allowing team tasks to be assigned to the people who are most able to perform them (Hollingshead, 1998; Moreland \& Myaskovsky, 2000).

Hypothesis 5: The level of shared awareness of expertise location has a positive effect on team performance.

In contrast, shared task understanding enhances team performance by bridging communication gaps that often exist within a team due to members' different experience backgrounds and expertise (Abdul-Gader \& Kozar, 1990; He et al., 2007). Communication gaps hinder collaboration in project teams. The formation of shared task understanding allows team members to interpret cues in a similar manner and make compatible decisions (Klimoski \& Mohammed, 1994; Mohammed \& Dumville, 2001). Therefore, shared task understanding reduces communication obstacles and facilitates intragroup coordination based on shared understanding of focal tasks rather than on the more problematic interpersonal communication (Vandenbosch \& Higgins, 1996). As a result, team performance will improve due to greater intragroup coordination.

Hypothesis 6: The level of shared task understanding has a positive effect on team performance.

Although team cognition may strongly mediate the effects of free-riding 
on team performance, previous studies have not assessed the extent of the mediation. I propose, as an exploratory study on the issue, that team cognition partially mediates the negative effects of free-riding on team performance.

Hypothesis 7: The scale of free-riding has a negative effect on team performance after controlling the effects of shared awareness of expertise location and shared task understanding.

\section{Research Design}

The study selected student software development teams as the research subject. Beyond the practical advantage of sampling convenience, the decision was made mainly for the expected homogeneity among student backgrounds, which would lower the risk of unexpected confounding effects caused by diversity among ages, experiences, organizational culture, management levels, etc.

A synthetic software development task was designed to test the research model. Synthetic tasks are "research tasks constructed by systematic abstraction from a corresponding realworld task" (Martin, Lyon, \& Schreiber, 1998 , p. 123). Performance on a synthetic task should exercise some of the same behavioral and cognitive skills associated with the real-world task, while avoiding the complexity (for example, the existence of various confounding factors that may lower the opportunity of observing significant effects of the investigated factors) encountered in an uncontrolled field study of real tasks.

The synthetic task employed in this study was the development of a relational database system using Microsoft Access. Except for team formation and task deadline, participants were free to set their own schedules and procedures to carry out their tasks, simulating the software development process in a realistic manner.

\begin{tabular}{|l|r|}
\hline \multicolumn{2}{|l|}{ Gender } \\
\hline Female & 143 \\
Male & 136 \\
Total & 279 \\
\hline \multicolumn{1}{|c|}{ Age } & \\
\hline $18-20$ & 115 \\
$21-25$ & 126 \\
26 and up & 38 \\
\hline Total & 279 \\
\hline Status & \\
\hline Junior & 67 \\
Senior & 181 \\
Fifth year & 31 \\
\hline Total & 279 \\
\hline
\end{tabular}

Table 1: Demographics of participants.

\section{Participants}

Two hundred and seventy-nine undergraduates who were enrolled in an information systems course formed teams to fulfill a course requirement of collaboratively developing a relational database system over a 5-week period. The demographics of participants are reported in Table 1.

When the project was assigned, students were instructed to form threemember teams and were allowed to make their own teammate selections. Some students selected acquaintances as teammates, while others chose students who happened to be seated nearby. Eighty-nine teams were formed: 9 teams with two members, 59 teams with three members, and 21 teams with four members.

\section{Data Collection}

Data were collected from two surveys distributed at the beginning and the end of the software development process. The purpose of designing two surveys was to reduce possible common-source bias by separating the measurement of predictors and dependent variables (Podsakoff, MacKenzie, Lee, \& Podsakoff, 2003). More specifically, participants were instructed to answer questions about their team morale during the first week of the project; just before the submission of their work, participants took the second survey with regard to the execution of their team tasks, including team members' participative activities, team cognition, and team performance.

Although encouraged by the course instructor, taking the survey was voluntary. Students were told that the survey responses would not influence their grades in any way. Some students failed to answer the survey on time, and some submitted incomplete answers. This resulted in 227 usable sets of individual data for analysis, or an $81 \%$ effective response rate.

\section{Measurement}

Free-Riding

So far, free-riding has been studied largely with mathematical models and conceptual discussions. In the sporadic empirical studies, free-riding is often investigated indirectly by circuitous observations. For example, Schnake (1991) assessed task performance, work motivation, and job satisfaction for personal efforts in group settings, and concluded that employees would likely shirk from team actions if they received negative social cues that other group members were withholding or tended to withhold personal efforts. Taggar and Neubert (2008) used observers to judge the scale of free-riding in a video of simulated team interaction. In a study of technology-supported teams, Alnuaimi and colleagues (2010) measured the number of ideas generated per person in a brainstorming team task as the proxy of free-riding. To my knowledge, there is no commonly accepted measure in the literature to directly assess the scale of free-riding in team settings.

Unlike other team-level measures such as team performance, free-riding is to detect and assess the undesirable shirking behaviors from few, not all, team members on assigned team tasks. Thus, a potential instrument should be carefully designed to capture the lowest level, rather than the average level, of participation among team members. 
Based on discussion with students as well as personal experience, I developed an instrument with two-step questions to measure the level of the lowest participation in teams. Students were first asked to identify a teammate who had contributed the least in their teams. Then, they were asked nine behaviorally anchored questions to assess the participation level of the teammate on key project activities. The activities include both teamwork (e.g., participating in team meetings and communicating with other team members) and task execution (e.g., contributing ideas and working on assignments). The rationale of this design was explained explicitly on the questionnaire: low levels of participation on project activities will be viewed as free-riding; if the reported participation of the least-involved teammate is of high levels, the team will be assessed with no or little free-riding.

\section{Other Measures}

In this study, team morale, team size, team cognition (including shared awareness of expertise location and shared task understanding), and team performance were measured to test the research model. Team morale was measured by a six-item instrument about members' attitudes (or the perceived importance) of their team assignments; shared awareness of expertise location and shared task understanding were each measured by a four-item instrument adopted from $\mathrm{He}$ et al. (2007). Team performance was measured by a five-item instrument adapted from Robey, Smith, and Vijayasarathy (1993). Individual responses of these measures were averaged within teams to form team-level data for testing.

These instruments are reported in the Appendix.

\section{Results}

\section{Construct Validity}

The test of construct validity was conducted with partial least squares (PLS) a structural equation modeling (SEM) technique that has been commonly used in information systems (IS) research. Similar to other SEM techniques (e.g., LISREL), PLS tests the validity of constructs and the structural model at the same time, and is therefore considered methodologically rigorous when compared with regression-based techniques that separate the test of construct validity (e.g., factor analysis) from the test of the research model (Gefen, Straub, \& Boudreau, 2000). Two other distinctive features of PLS made the technique a particularly suitable testing tool for this study:

1. PLS has the flexibility of accepting single-item constructs (i.e., team size in this study).

2. The algorithm of PLS, which is component-based rather than covariance-based, allows the modeling of formative indicators (Chin, 1998). In this study, the construct of freeriding was modeled as formative indicators based on its conceptualization and operationalization (questions asking the performance of a certain set of activities).

The design of the new instrument of free-riding suggests the measure be modeled as a formative indicator in hypothesis testing. Conventional procedures used to assess the validity of reflective constructs (e.g., factor analysis) may not be appropriate for assessing the validity of formative constructs (Diamantopoulos \& Winklhofer, 2001). In this study, a multitrait-multimethod (MTMM) method with special modification for assessing formative constructs (Loch, Straub, \& Sherif, 2003) was used to examine the convergent and discriminant validity of a new measure of free-riding. This method is also practiced in Marakas, Johnson, and Clay (2007) for the development of different types of computer selfefficacy.

In this method, a composite score of each formative indicator was calculated based on the sum of products between its formative items and their associated weights. The weight represents the extent to which an item contributes to the overall value of a latent variable. A correlation matrix is then calculated between items of formative constructs and all constructs under study. To establish convergent validity, items should correlate high with items measuring the same construct, and low with items measuring other constructs. To establish discriminant validity, items should correlate high with the assigned constructs and low with unassigned ones. Following the guideline, the resulted correlation matrix was examined and all the aforementioned rules were satisfied. Thus, the validity of the formative construct of free-riding was concluded.

Assessing the validity of reflective items follows the conventional practice based on the examination of construct reliability, convergent validity, and discriminant validity. Construct validity can be assessed by composite reliability calculated in PLS (should be larger than 0.70). Convergent validity can be assessed by the average variance extracted (AVE) among measures (should be larger than 0.50). Discriminant validity can be assessed by comparing the square root of AVEs and interconstruct correlations-the former should be larger than the latter to support discriminant validity. Close examination of Table 2 suggested that all the conditions were satisfied. Thus, validity of the reflective indicators under study was concluded.

\section{Hypothesis Testing}

The research model was tested with PLS-Graph 3.0. Examination of the resulted statistics (path coefficients and their associated $p$-values) suggested that:

- H1 received strong support from the data sample. $\mathrm{H} 1$ hypothesizes that team morale has a negative effect on the scale of free-riding behavior in a team. The negative effect was found to be large in magnitude $(\beta=-0.567)$ and strong in significance $(p<0.001$, two-sided). 


\section{Counteracting Free-Riding With Team Morale}

\begin{tabular}{|c|c|c|c|c|c|c|c|}
\hline & Reliability & 1 & 2 & 3 & 4 & 5 & 6 \\
\hline 1. Team morale & 0.97 & 0.926 & $\ldots$ & $\ldots$ & $\ldots$ & $\ldots$ & $\ldots$ \\
\hline 2. Team size & 1 & -0.060 & 1 & $\ldots$ & $\ldots$ & $\ldots$ & $\ldots$ \\
\hline 3. Free-riding ${ }^{a}$ & - & -0.557 & -0.136 & $\ldots$ & $\ldots$ & $\ldots$ & $\ldots$ \\
\hline 4. Expertise location & 0.96 & 0.421 & -0.150 & -0.561 & 0.922 & $\ldots$ & $\ldots$ \\
\hline 5. Task understanding & 0.95 & 0.491 & -0.141 & -0.570 & 0.746 & 0.907 & $\ldots$ \\
\hline 6. Team performance & 0.96 & 0.480 & -0.234 & -0.475 & 0.769 & 0.712 & 0.902 \\
\hline \multicolumn{8}{|c|}{$\begin{array}{l}\text { Note. Reliability: composite reliability is calculated in PLS. Numbers in bold on the leading diagonal are the square root of the average variance extracted (AVE) among } \\
\text { reflective measures. For discriminant validity of constructs, diagonal elements should be larger than off-diagonal elements. Off-diagonal elements are correlations } \\
\text { among constructs. } \\
\text { aFree-riding is modeled as formative indicators in the study. Calculations of construct reliability and shared variance are not relevant for the construct. }\end{array}$} \\
\hline
\end{tabular}

- $\mathrm{H} 2$ received marginal support from the data sample. $\mathrm{H} 2$ predicts that free-riding will be more manifest in large teams than that in small teams. The positive effect of team size on the scale of free-riding was found to be moderately small $(\beta=0.17)$ and marginally significant ( $p=0.072$, two-sided).

- H3 and H4 both received strong support from the data sample. The two hypotheses propose that free-riding has negative effects on team cognition in terms of shared awareness of expertise location (H3) and shared task understanding (H4). The negative effects were found to be large in magnitude $(\beta=-0.561$ for $\mathrm{H} 3$ and $\beta=$ -0.570 for $\mathrm{H} 4$ ) and strong in significance (both with $p<0.001$, two-sided).

- H5 and H6 also received strong support from the data sample. The two hypotheses propose that team cognition, measured by shared awareness of expertise location (H5) and shared task understanding (H6), exerts positive effects on team performance. Both path coefficients were found to be substantial ( $\beta=0.538$ for H5 and $\beta=0.314$ for H6) with distinct statistical significance ( $p<0.001$ for $\mathrm{H} 5$ and $p<0.01$ for H6, two-sided).

- $\mathrm{H} 7 \mathrm{did}$ not receive support from the data sample. $\mathrm{H} 7$ states that free-riding presents a negative effect on team performance after controlling the effects of two key elements of team cognition (i.e., shared awareness of expertise location and shared task understanding). The hypothesized effect was found to be negligible $(\beta=$ $-0.07, p=0.478$ ), suggesting that in the research sample team cognition fully mediated the influence of freeriding on team performance.

Overall, testing results lent strong support to the proposed research model. Most relationships were concluded with hypothesized directions and statistical significance; in addition, about $34 \%$ variance of free-riding and $63 \%$ variance of team performance were explained by the model. These statistics demonstrate good model fit (Gefen et al., 2000). The testing results are summarized in Figure 2.

\section{Summary and Discussion}

\section{Summary of the Findings}

There is little doubt that free-riding exerts deteriorating effects on collective actions. But to what extent does freeriding impair team performance? Data from the sampled student software development teams shows that the negative effect of free-riding on team performance is considerably large $(r=$ $-0.475, p<0.001)$. Such an effect is fully mediated by team cognition (measured by shared awareness of expertise location and shared task understanding). This finding suggests that the free-rider problem impairs team performance by impeding the development of collective mental models among team members.

In this study, both team size and team morale were measured at the

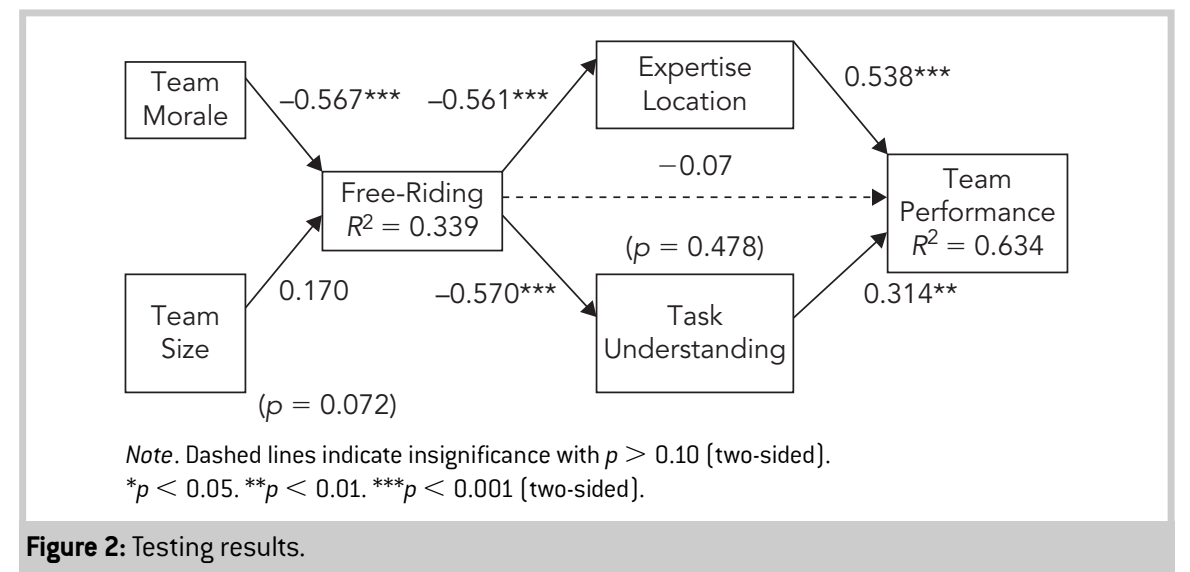


beginning of the software development process when research participants formed their teams for the target project. As expected, team morale was found to be negatively associated with, and team size was positively associated with, the scale of free-riding in the sampled teams. This result suggests that enhancing team morale and reducing team size are two effective means for counteracting the free-riding tendency among team members. The two means can be carefully applied to project management during early stages of project development before the commitment of significant resources.

One appropriate situation to enhance team morale will be the kickoff meeting for a new project. Starting a project with a kick-off meeting is a common project management practice. The main purpose of the first team meeting is to clearly understand team tasks (Wright, 2009), assign roles and responsibilities (West, 2004), and create and maintain effective working relationships among team members (Bandow, 2001). This study suggests that enhancing team morale should be another valuable pursuit of the meeting. High team morale helps to counter the propensity of free-riding in future team activities, and therefore increases the chance for the team to achieve quality performance. Thus, the meeting agenda should place special emphasis on members' attitudes toward team tasks. Means such as helping team members to realize that their goals are entwined with that of the team should be highly advocated to motivate work teams (Gowen, 1985) for high levels of team morale.

In the study, the effect of team size was concluded to be of marginal significance ( $p=0.072$ in Figure 2), suggesting that reducing team size could be another effective method of counteracting free-riding. However, team size is often determined by project scale and therefore difficult to be manipulated. For example, in the development of complex information systems, project execution typically requires knowledge and experience from many domains (Curtis, Krasner, \& Iscoe, 1988; Faraj \& Sproull, 2000), leading to an inevitable use of large project teams. One feasible solution will be to divide a large project into parts featured by product functions, features, or subsystems, and employ small workgroups to work on these parts in a coordinated fashion. This approach has been successfully practiced in the development of complex software at Microsoft (Cusumano, 1997) and is a key element of Agile methodologies that have received increasing attention, especially in information systems development (Nerur, Mahapatra, \& Mangalaraj, 2005). Major challenges to the approach include coordination among workgroups and integration test of the final product (Sangwan \& Laplante, 2006). In addition to the merits of dealing with project uncertainties (caused by dynamic project environment, evolving technologies and development tools, and/or changing user requirements) and speeding up the project development process (Nerur et al., 2005), the approach of employing small workgroups should be advocated for its potential of counteracting the free-riding tendency among team members. This will be particularly effective in large project teams where free-riding exerts a severe threat to team performance due to the diluted attention on individual participation.

\section{Suggestions to Future Research}

Due to the scope of the research, other means for counteracting free-riding behaviors were not investigated. One of such means may be an individual's identification with his or her working team. Individuals can identify with multiple actors (organizations, unions, supervisors, committees, siblings), and their behavioral choices are dependent upon the strength of their identification with each of these actors (Brickson, 2000). The stronger one's identification with a team, the more committed the person will be toward the team's objectives (Pelled, Eisenhardt, \& Xin, 1999), and therefore the less likely the person will shirk from collective actions. This will be a promising area for future research on free-riding.

The study does not investigate team leadership, another important means of counteracting free-riding behaviors in project teams. Empirical evidence has repeatedly demonstrated that leadership plays a key role in regulating team behavior and directing task execution toward satisfactory outcomes (Carte, Chidambaram, \& Becker, 2006; Morgeson, DeRue, \& Karam, 2010). However, leadership research has paid little attention to free-riding. A common view of team leadership is that of “... leader as completer ... the best a leader can do is to observe which functions are not being performed by a segment of the group and enable this part to accomplish them" (Schutz, 1961, p. 61). The theory of transformational leadership also emphasizes the role of team leaders in shaping members' collective behavior by inspiring commitment and sacrifice for the group (Burns, 1978). Thus, effective team leaders are expected to restrain and eliminate free-riding behaviors among team members, but practical guide lines that managers can follow are rare in the literature (Albanese \& Van Fleet, 1985). It must be desirable for future research to investigate the role of team leadership in counteracting free-riding. Such research will enrich our understanding of team leadership and provide strong implications for the practice of project management.

Another interesting area for future research could be the effects of demographics on free-riding. The literature on team diversity suggests that the distribution of demographics such as ethnicity, age, and gender may influence one's behavior in work teams. In a study of team cognition in software development teams, mixed-gender teams were found to develop higher levels of team cognition than that of single-gender 


\section{Counteracting Free-Riding With Team Morale}

teams (He et al., 2007). Distinct behavioral patterns induced by team diversity may exist in the phenomenon of freeriding. The demographics of participating students are reported in Table 1. However, due to the scope of study, team diversity effects were not investigated. Future research needs to clarify the issue.

The research model does not include a time variable, which has recently received increased attention in IS research (Sarker \& Sahay, 2004; Saunders, 2007). The team literature has long recognized the influence of time on team behavior (Tuckman, 1965; Wheelan \& Hochberger, 1996). For example, the team transition model (Gersick, 1989) argues that the urgency of deadlines helps teams alternate the inertia in team behaviors and themes through which they approach their work. As time passes, the awareness of deadlines will alert team members to the necessity of adjusting their behaviors to assure the project is completed on schedule. Thus, one may expect that team morale will increase, and free-riding will decrease, with the progress of the project.

To clarify the issue, additional surveys were distributed during the fiveweek project development period. Every week, participants were asked the same questions of team morale and free-riding in their teams. The results are summarized in Table 3.

The results suggest insignificant correlations between the time of measurement and the scales of team morale and free-riding ( $p$-values are 0.456 and 0.657 , respectively). The previously mentioned time effects were not observed in the sampled teams. Future research is needed to clarify the effect of time on team morale and free-riding.

\section{Limitations of the Study}

Although the results are encouraging, the study has several limitations. One is about the measurement of free-riding. Free-riding was measured by a new instrument rather than an existing measure from the literature. Viewing

\begin{tabular}{|c|c|c|c|c|c|}
\hline & & \multicolumn{2}{|c|}{ Team Morale } & \multicolumn{2}{|c|}{ Free-Riding } \\
\hline & & Mean & Std. & Scale $^{a}$ & Std. \\
\hline \multirow{5}{*}{$\begin{array}{l}\text { Time of } \\
\text { Measurement }\end{array}$} & Week 1 & 4.22 & 0.47 & 0.68 & 1.40 \\
\hline & Week 2 & 4.25 & 0.60 & 0.62 & 1.27 \\
\hline & Week 3 & 4.21 & 0.43 & 0.52 & 1.20 \\
\hline & Week 4 & 4.23 & 0.54 & 0.41 & 1.50 \\
\hline & Week 5 & 4.33 & 0.42 & 0.63 & 1.19 \\
\hline \multicolumn{2}{|c|}{ Correlation With Time } & \multicolumn{2}{|c|}{0.063} & \multicolumn{2}{|c|}{-0.037} \\
\hline
\end{tabular}

aFree-riding is modeled as formative indicators in the study; its scale is calculated using path weights of each measurement item calculated in PLS.

Table 3: Time effects on team morale and free-riding.

free-riding as lack of participation in team settings, the instrument adopts a formative measurement approach and employs a set of behavior-anchored questions to assess the scale of freeriding. The development of the new instrument can be viewed as a contribution to the field; however, the validity of the new instrument needs to be tested with confirmatory analysis such as confirmatory factor analysis (CFA) in future research.

Another limitation is the low variance among the sizes of teams being investigated in the study. The sampled teams had two, three, or four members in each team, while in actual projects the use of large teams with dozens of members is not rare. Although a natural limitation of experimental study, the results of the current research do reveal the effect of team size on free-riding. The conclusion needs further empirical support, especially from field studies conducted in real business settings.

All the constructs except team size were self-reported by participating students. Thus, common method bias could be another concern for the study. By aggregating individual responses to form team-level measures, this concern may be alleviated in that multiple responses could cancel out each other's errors. To assess the extent of common method variance, I performed
Harman's single-factor test by loading all of the items in this study into an exploratory factor analysis. Although the Harman method is a widely used diagnostic technique, Podsakoff and colleagues (Podsakoff et al., 2003) criticized it for its ambiguity about the source of the variance extracted by a single factor. The extracted variance from the single factor could be caused by the use of a common method, lack of discriminant validity, and/or the existence of causal relationships among the investigated constructs.

To assess the source of the extracted variance, I performed two Harman's single-factor tests with the objective measure of team size included and excluded, respectively. With team size included, an emerged single factor explained $36.81 \%$ of the covariance among the measures. With team size excluded, the variance extracted from a single factor increased to $37.95 \%$. The trivial difference (about $1.1 \%$ of the total variance) provides strong evidence that there is no substantial common method variance present.

As this was an experimental study, student teams were selected as the research subject. Thus, special caution is needed when applying the findings to teams of other settings. Student teams differ from other teams in many ways. For example, the incentive systems are 
weak in student teams because of the lack of severe consequence of poor performance; but in real business settings, failing to meet coworkers' expectations is likely to affect the prosperity of one's career. Also, the sampled student teams involve no geographically distributed participants, and team communication relies mainly on face-to-face meetings and e-mails, while companies are increasingly adopting virtual teams enabled by the development of group communication technologies (Bjørn \& Ngwenyama, 2009). Future research is desired to test the generalizability of the findings in various contexts.

\section{References}

Abdul-Gader, A. H., \& Kozar, K. A. (1990). Discourse analysis for knowledge acquisition: The coherence method. Journal of Management Information Systems, 6(4), 61-82.

Albanese, R., \& Van Fleet, D. D. (1985). Rational behavior in groups: The freeriding tendency. Academy of Management Review, 10(2), 244-255.

Alnuaimi, O. A., Robert, L. P., \& Maruping, L. M. (2010). Team size, dispersion, and social loafing in technology-supported teams: A perspective on the theory of moral disengagement. Journal of Management Information Systems, 27(1), 203-230.

Andreoni, J., Harbaugh, W., \& Vesterlund, L. (2003). The carrot or the stick: Rewards, punishments and cooperation. American Economic Review, 93(3), 893-902.

Anesi, V. (2009). Moral hazard and free riding in collective action. Social Choice and Welfare, 32(2), 197-219.

Bandow, D. (2001). Time to create sound teamwork. Journal for Quality and Participation, 24(2), 41-47.

Bjørn, P., \& Ngwenyama, O. (2009). Virtual team collaboration: Building shared meaning, resolving breakdowns and creating translucence. Information Systems Journal, 19(3), 227-253.

Brickson, S. (2000). The impact of identity orientation individual and organizational outcomes in demographically diverse settings. Academy of Management Review, 25(1), 82-101.

Burns, J. M. (1978). Leadership. New York, NY: Harper and Row.

Cannon-Bowers, J. A., \& Salas, E. (2001). Reflections on shared cognition. Journal of Organizational Behavior, 22(2), 195-202.

Cannon-Bowers, J. A., Salas, E., \& Converse, S. (1993). Shared mental models in expert team decision making. In N. J. Castellan (Ed.), Individual and group decision making (pp. 221-246). Hillsdale, NJ: Lawrence Erlbaum Associates.

Carte, T. A., Chidambaram, L., \& Becker, A. (2006). Emergent leadership in selfmanaged virtual teams: A longitudinal study of concentrated and shared leadership behaviors. Group Decision and Negotiation, 15(4), 323-343.

Chidambaram, L., \& Tung, L. L. (2005). Is out of sight, out of mind? An empirical study of social loafing in technology-supported groups. Information Systems Research, 16(2), 149-168.

Chin, W. W. (1998). Issues and opinion on structural equation modeling. MIS Quarterly, 22(1), vii-xvi.

Cooke, N. J., Salas, E., Kiekel, P. A., \& Bell, B. (2004). Advances in measuring team cognition. In E. Salas \& S. M. Fiore (Eds.), Team cognition: Understanding the factors that drive process and performance (pp. 83-106). Washington, DC: American Psychological Association.

Curtis, B., Krasner, H., \& Iscoe, N. (1988). A field study of the software design process for large systems. Communications of the ACM, 31(11), 1268-1287.

Cusumano, M. A. (1997). How

Microsoft makes large teams work like small teams. Sloan Management

Review, 39(1), 9-20.

Dawes, R. M. (1980). Social dilemmas. Annual Review of Psychology, 31, 169-193.

Dawes, R. M., McTavish, J., \& Shaklee, H. (1977). Behavior, communication, and assumptions about other people's behavior in a commons dilemma situation. Journal of Personality and Social Psychology, 5(1), 1-11.

Diamantopoulos, A., \& Winklhofer, H. M. (2001). Index construction with formative indicators: An alternative to scale development. Journal of Marketing Research, 38(2), 269-277.

Edney, J. J. (1980). The commons problem: Alternative perspectives. American Psychologist, 35(2), 131-150.

Faraj, S., \& Sproull, L. (2000). Coordinating expertise in software development teams. Management Science, 46(12), 1554-1568.

Feather, N. T., \& Rauter, K. (2004). Organizational citizenship behaviours in relation to job status, job insecurity, organizational commitment, and identification, job satisfaction and work values. Journal of Occupational and Organizational Psychology, 77(1), 81-94.

Fehr, E., \& Gächter, S. (2000).

Cooperation and punishment in public goods experiments. American Economic Review, 90(4), 980-994.

Foote, D. A., \& Tang, T. L. (2008). Job satisfaction and organizational citizenship behavior (OCB); Does team commitment make a difference in selfdirected teams? Management Decision, 46(6), 933-947.

Gefen, D., Straub, D. W., \& Boudreau, M. (2000). Structural equation modeling techniques and regression: Guidelines for research practice. Communications of the Association for Information Systems, 4(7), 1-78.

Gersick, C.J.G. (1989). Making time: Predictable transitions in task groups. Academy of Management Journal, 32(2), 274-309.

Glassop, L. I. (2002). The organizational benefits of teams. Human Relations, 55(2), 225-249.

Gowen, C. R., III. (1985). Managing work group performance by individual goals and group goals for an interdependent group task. Journal of Organizational Behavior Management, 7(3/4), 5-27. 
Hawkes, K. (1993). Why huntergatherers work-An ancient version of the problem of public goods. Current Anthropology, 34(4), 341-361.

He, J., Butter, B. S., \& King, W. R. (2007). Team cognition: Development and evolution in software project teams. Journal of Management Information Systems, 24(2), 261-292.

Hoffman, B. J., Blair, C. A., Meriac, J. P., \& Woehr, D. J. (2007). Expanding the criterion domain? A quantitative review of the OCB literature. Journal of Applied Psychology, 92(2), 555-566.

Hollingshead, A. B. (1998). Group and individual training: The impact of practice on performance. Small Group Research, 29(2), 254-280.

Jackson, S. E., May, K. E., \& Whitney, K. (1995). Understanding the dynamics of diversity in decision making teams. In R. A. Guzzo \& E. Salas (Eds.), Team effectiveness and decision making in organizations (pp. 204-261). San Francisco, CA: Jossey-Bass.

Jones, G. R. (1984). Task visibility, free riding, and shirking: Explaining the effect of structure and technology on employee behavior. Academy of Management, 9(4), 684-695.

Kappelman, L. A., McKeeman, R., \& Zhang, L. (2006). Early warning signs of IT project failure: The dominant dozen. Information Systems Management, 23(4), 31-36.

Karau, S. J., \& Williams, K. D. (1993). Social loafing: A meta-analytic review and theoretical integration. Journal of Personality and Social Psychology, 65(4), 681-706.

Katz, R., \& Tushman, M. (1979). Communication patterns, project performance, and task characteristics: An empirical evaluation and integration in an R\&D setting. Organizational Behavior and Human Performance, 23(2), 139-162.

Kerr, N. (1983). Motivation losses in small groups: A social dilemma analysis. Journal of Personality and Social Psychology, 45(4), 819-828.
Kidwell, R. E., Jr., \& Bennett, N. (1993). Employee propensity to withhold effort: A conceptual model to intersect three avenues research. Academy of Management Review, 18(3), 429-456.

Kim, S. (2006). Public service motivation and organizational citizenship behavior in Korea. International Journal of Manpower, 27(8), 722-740.

King, W. R., \& He, J. (2005). External validity in IS survey research. Communications of the Association for Information Systems, 16, Article 45, 880-894.

Klimoski, R., \& Mohammed, S. (1994). Team mental model: Construct or metaphor? Journal of Management, 20(2), 403-437.

Knoke, D. (1988). Incentives in collective action organizations. American Sociological Review, 53(3), 311-329.

Latane, B. (1981). The psychology of social impact. American Psychologist, 36(4), 343-356.

Lewis, K. (2004). Knowledge and performance in knowledge-worker teams: A longitudinal study of transactive memory systems. Management Science, 50(11), 1519-1533.

Liang, D. W., Moreland, R. L., \& Argote, L. (1995). Group versus individual training and group performance: The mediating role of transactive memory. Personality and Social Psychology Bulletin, 21(4), 384-393.

Lindsay, W. M., Manning, G. E., \& Petrick, J. A. (1991). Mapping work group morale. Journal for Quality and Participation, 14(2), 100-106.

Loch, K. D., Straub, D. W., \& Sherif, K. (2003). Diffusing the internet in the Arab world: The role of social norms and technological culturation. IEEE Transactions on Engineering Management, 50(1), 45-63.

Luce, R. D., \& Raiffa, H. (1957). Games and decisions. New York, NY: Wiley.

MacMillan, J., Estin, E. E., \& Serfaty, D. (2004). Communication overhead: The hidden cost of team cognition. In E. Salas \& S. M. Fiore (Eds.), Team cognition: Understanding the factors that drive process and performance (pp. 61-82). Washington, DC: American Psychological Association.

Marakas, G. M., Johnson, R. D., \& Clay, P. F. (2007). The evolving nature of the computer self-efficacy construct: An empirical investigation of measurement construction, validity, reliability and stability over time. Journal of the Association for Information Systems, 8(1), 15-46.

Martin, E., Lyon, D. R., \& Schreiber, B. T. (1998). Designing synthetic tasks for human factors research: An application to uninhabited air vehicles. In Proceedings of the Human Factors and Ergonomics Society 42nd Annual Meeting (pp. 123-127). Santa Monica, CA: Human Factors and Ergonomics Society.

Mathieu, J. E., Goodwin, G. F., Heffner, T. S., Salas, E., \& Cannon-Bowers, J. A. (2000). The influence of shared mental models on team process and performance. Journal of Applied Psychology, 85(2), 273-283.

Meyer, G. W. (1994). Social information processing and social networks: A test of social influence mechanisms.

Human Relations, 47(9), 1013-1047.

Meyer, J. P., \& Herscovitch, L. (2001). Commitment in the workplace: Toward a general model. Human Resource Management Review, 11(3), 299-326.

Mohammed, S., \& Dumville, B. C. (2001). Team mental models in a team knowledge framework: Expanding theory and measurement across disciplinary boundaries. Journal of Organizational Behavior, 22(2), 89-106.

Moorman, R. H., \& Harland, L. K. (2002). Temporary employees as good citizens: Factors influencing their OCB performance. Journal of Business and Psychology, 17(2), 171-187.

Moreland, R. L., \& Myaskovsky, L. (2000). Exploring the performance benefits of group training: Transactive memory or improved communication? Organizational Behavior \& Human Decision Processes, 82(1), 117-133. 
Morgeson, F. P., DeRue, D. S., \& Karam, E. P. (2010). Leadership in teams: A functional approach to understanding leadership structures and processes. Journal of Management, 36(1), 5-39.

Murnighan, J. K., \& Conlon, D. E. (1991). The dynamics of intense work groups: A study of British string quartets. Administrative Science Quarterly, 36(2), 165-186.

Nerur, S., Mahapatra, R. K., \& Mangalaraj, G. (2005). Challenges of migrating to agile methodologies. Communications of the ACM, 48(5), 73-78.

Olson, M. (1965). The logic of collective action. Cambridge, MA: Harvard University Press.

Orbell, J., \& Dawes, R. (1981). Social dilemmas. In G. Stephenson \& J. H. Davis (Eds.), Progress in applied social psychology (Vol. 1, pp. 37-65). Chichester, UK: Wiley.

Organ, D. W. (1988). Organizational citizenship behavior. Lexington, MA: D.C. Heath and Co.

Organ, D. W., Podsakoff, P. M., \& MacKenzie, S. B. (2006).

Organizational citizenship behavior: Its nature, antecedents, and consequences. Thousand Oaks, CA: Sage.

Organ, D. W., \& Ryan, K. (1995). A meta-analytic review of attitudinal and dispositional predictors of organizational citizenship behavior. Personnel Psychology, 48(4), 775-803.

Ouchi, W. G. (1980). Markets, bureaucracies, and clans. Administrative Science Quarterly, 25(1), 129-141.

Paillé, P. (2010). Citizenship in the workplace: Examining work attitudes as predictors among French employee. International Journal of Business and Management, 5(4), 53-64.

Pelled, L. H., Eisenhardt, K. M., \& Xin, K. R. (1999). Exploring the black box: An analysis of work group diversity, conflict, and performance. Administrative Science Quarterly, 44(1), 1-28.

Platt, J. (1973). Social traps. American Psychologist, 28(8), 641-651.
Podsakoff, P. M., MacKenzie, S. B., Lee, J. Y., \& Podsakoff, N. P. (2003).

Common method biases in behavioral research: A critical review of the literature and recommended remedies. Journal of Applied Psychology, 88(5), 879-903.

Price, M. E. (2006). Judgments about cooperators and freeriders on a Shuar work team: An evolutionary psychological perspective. Organizational Behavior and Human Decision Processes, 101(1), 20-35.

Randall, M. L., Cropanzano, R., Bormann, C. A., \& Birjulin, A. (1999). Organizational politics and organizational support as predictors of work attitudes, job performance, and organizational citizenship behavior. Journal of Organizational Behavior, 20(2), 159-174.

Riopelle, K., Gluesing, J., Alcordo, T., Baba, M., Britt, D., McKether, W., . . . \& Wagner, K. H. (2003). Context, task, and the evolution of technology use in global virtual teams. In C. B. Gibson \& S. G. Cohen (Eds.), Virtual teams that work (pp. 239-264). Hoboken, NJ: Jossey-Bass.

Robey, D., Smith, L. A., \& Vijayasarathy, L. R. (1993). Perceptions of conflict and success in information systems development projects. Journal of

Management Information Systems, 10(1), 123-139.

Runge, C. F. (1984). Institutions and the free rider: The assurance problem in collective action. Journal of Politics, 46(1), 154-181.

Salancik, G., \& Pfeffer, J. (1978). A social information processing approach to job attitudes and task design. Administrative Science Quarterly, 23(2), 224-253.

Sangwan, R. S., \& Laplante, P. A. (2006). Test-driven development in large projects. IT Professional Magazine, 8(5), 25-29.

Sarker, S., \& Sahay, S. (2004). Implications of space and time for distributed work: An interpretive study of US-Norwegian systems development teams. European Journal of

Information Systems, 13(1), 3-20.

Saunders, C. (2007). Editor's comments: Perspectives on time. MIS Quarterly, 31(4), iii-xi.

Schnake, M. E. (1991). Equity in effort: The "sucker effect" in co-acting groups. Journal of Management, 17(1), 41-55.

Schutz, W. C. (1961). The ego, FIRO theory and the leader as completer. In L. Petrullo \& B. M. Bass (Eds.), Leadership and interpersonal behavior (pp. 48-65). New York, NY: Rinehart \& Winston, Holt.

Simon, H. (1976). Administrative behavior (3rd ed.). New York, NY: Free Press.

Stroebe, W., \& Frey, B. S. (1982). Selfinterest and collective action: The economics and psychology of public goods. British Journal of Social Psychology, 21(2), 121-137.

Taggar, S., \& Neubert, M. J. (2008). A cognitive (attributions)-emotion model of observer reactions to free-riding poor performers. Journal of Business and Psychology, 22(3), 167-177.

Tuckman, B. W. (1965). Developmental sequences in small groups.

Psychological Bulletin, 63(6), 384-399.

van Dijk, F., Sonnemans, J., \& van

Winden, F. (2001). Incentive systems in a real effort experiment. European Economic Review, 45(2), 187-214.

Vandenbosch, B., \& Higgins, C. (1996). Information acquisition and mental models: An investigation into the relationship between behaviour and learning. Information Systems Research, 7(2), 198-214.

Vilela, B. B., González, J. A. V., \& Ferrín, P. F. (2008). Person-organization fit, OCB and performance appraisal: Evidence from matched supervisorsalesperson data set in a Spanish context. Industrial Marketing Management, 37(8), 1005-1019.

Walsh, J. P. (1995). Managerial and organizational cognition: Notes from a trip down memory lane. Organization Science, 6(3), 280-321. 


\section{Counteracting Free-Riding With Team Morale}

West, M. (2004). Motivate teams, maximize success: Effective strategies for realizing your goals. San Francisco, CA: Chronicle Books.

Wheelan, S. A., \& Hochberger, J. M. (1996). Validation studies of the group development questionnaire. Small Group Research, 27(1), 143-170.

Williamson, O. E. (1985). The economic institutions of capitalism: Firms, markets, relational contracting. New York, NY: Free Press.
Wright, R. (2009). Effective kickoff meetings. The Internal Auditor, 66(2), 21-23.

Yamagishi, T. (1986). The provision of a sanctioning system as a public good. Journal of Personality and Social Psychology, 51(1), 110-116.

Jun He is an assistant professor of MIS and information technology management at the University of Michigan-Dearborn. He has an MBA from Tsinghua University and a PhD degree from the
University of Pittsburgh. His research interests include systems design and development, knowledge management, and methodological issues. He has presented a number of papers at meetings of the Association for Computing Machinery (ACM) and the Americas' Conference on Information Systems (AMCIS), published in journals such as Communications of the Association for Information Systems, Information and Management, and Journal of Management Information Systems; and in two books, Current Topics in Management and Planning for IS. 


\section{Appendix}

Free-Riding (a Two-Step Measure)

Step 1: Recall the whole project development process. Select a member who has contributed to the project the least in your group (other than you). Note: if the person you selected has contributed a lot (as reflected in the next set of questions), it means that everyone has worked hard on this project and there is no free-rider on your team.

Step 2: Do you agree with the following statements regarding the person's contribution to the project?

1. The person did NOT participate in group meetings.

2. The person did NOT communicate with other members.

3. The person could NOT be reached by e-mail or telephone.

4. The person did NOT take responsibility for his/her part of the project development.

5. The person did NOT contribute any creative ideas to the project.

6. The person did provide meaningful suggestions/advice to the project.

7. The person's knowledge has great significance to this project.

8. Compared with my efforts, I think the person has contributed significantly to the group project.
9. Overall, the person has contributed a lot to this project.

Team Morale (a Collective Measure of Attitudes Toward Team Assignments)

Do you agree that you and your fellow members believe...

1. This assignment is important to all team members.

2. Everyone should work hard on this assignment.

3. Everyone should commit heavily to this assignment.

4. Nobody should "escape" from doing the assignment.

5. Teamwork is important to your group's success.

6. People should work closely to get the job done.

\section{Shared Awareness of Expertise}

\section{Location}

Do your team members know each other's skills and expertise ...

1. The team had a good "map" of each other's talents and skills.

2. Team members were assigned to tasks commensurate with their taskrelevant knowledge and skill.

3. Team members knew what taskrelated skills and knowledge they each possess.
4. Team members knew who on the team has specialized skills and knowledge that is relevant to their work.

\section{Shared Task Understanding}

Do you agree with the following statements?

1. Team members had a common understanding of the application domain (i.e., inventory management) that the system was supposed to support.

2. Team members had a common understanding of the technologies used in the development process.

3. Team members had a common understanding of the project development procedures.

4. Overall, team members shared their visions of the project.

\section{Team Performance}

Please evaluate performance of the project team in the past one week regarding...

1. The amount of work the team produced.

2. The efficiency of team operations.

3. The team's adherence to the schedule.

4 . The quality of work the team produced.

5. The effectiveness of the team's interactions with people outside the team. 